dr. Ana Krajnc

Filozofska

fakulteta $v$

Ljubljani

\section{SPONTANO INDIVIDUALNO IZOBRAŽEVANJE}

\section{Nekatera teoretična izhodišča}

Raziskave Alena Thomasa iz Kanade døkazujejo, da ljudje, ko jim zmanjka znanja, uberejo svoje poti in se to, kar potrebujejo, naučijo. Mnogi pri tem, če so brez mentorja in zunanjega vodenja, zaidejo v slepo ulico, izgubljajo dragoceni čas in ne pridejo pravočasno do potrebnega znanja. Nekateri pa so zelo uspešni. Dodatna podpora andragoških ustanov spontanemu izobraževanju bi zelo pripomogla k uspešnosti učenja.

čilne za družbeno ureditev do devetdesetih let, centralizirana tudi izobraževalna ponudba. Skoraj 60 odstotkov organizirane izobraževalne ponudbe je osredotočene na Ljubljano. V manjših krajih in po vaseh so možnosti za organizirano izobraževanje zelo majhne.
Zato so pri pridobivanju novih oblik znanja najbolj ogroženi prebivalci podeželja.

Pri spontanem, osebnem iskanju novega znanja so najuspešnejši tisti, ki uporabijo za pridobivanje znanja vire $\mathrm{v}$ svojem neposrednem okolju (sprašujejo sosede, se pogovorijo s partnerjem, telefonirajo prijateljem, $\mathrm{v}$ domačem kraju poiščejo in si ogledajo to, kar bi se radi naučili, sposodijo si priročnik o tem, kar bi se radi naučili, sodelujejo z drugimi, ki so jim dovolj blizu in jim zaupajo, itd.).

Tako se v določenem kraju izluščijo najuspešnejši vzorci in strategije spontanega izobraževanja. Večina ljudi se zgleduje po določeni osebi, nekateri se ne morejo obrniti na nikogar. Obstajajo pa tudi kraji, kjer so odnosi med ljudmi dobri in znanje zelo hitro kroži, zlasti med sosedi, s pogovori, posnemanjem, zgledovanjem po drugih itd. Če je v kraju branje časopisov $\mathrm{v}$ navadi in so mediji zelo popularni, ljudje tudi pri svojem spontanem izobraževanju ubirajo te poti.

Najuspešnejši vzorci in strategije spontanega izobraževanja se začnejo širiti, ponavljati in ljudje jih posnemajo. Pri spontanem osebnem izobraževanju so ljudje pozorni tudi na svoj uspeh pri učenju. Vrednotijo in presojajo, koliko so se sploh naučili, ali kaj znajo in koliko novega že vedo. Tako opazujejo tudi druge okrog sebe in če pri njih odkrijejo, da so se nečesa naučili, jih posnemajo.

Pogosto se posameznik svojega spontanega izobraževanja ne zaveda in izobraževalni načrt ni vedno dovolj domišljen. Posameznik 
Čas med nastalo potrebo po znanju in tem, da mora imeti posameznik novo znanje že pri roki, se čedalje bolj krajša. Pomembno je, da se to, kar potrebujemo, naučimo pravočasno, in ne kadarkoli. Zato je tudi v Sloveniji vse oěitnejšsa nujnost, da andragoške ustanove uvedejo in organizirajo službe za izobraževalno ali andragoško svetovanje in vodenje.

čuti, da znanje potrebuje, da ga neznanje $\mathrm{v}$ življenju ovira. Zato išče, kje bi spoznal to, kar potrebuje, a pri tem ni dovolj učinkovit.

$\mathrm{V}$ informacijski družbi se povečuje pomen individualnosti, ceni se posameznikova ustvarjalnost in inovativnost. Zato naj bi se $\mathrm{z}$ vzgojo in izobraževanjem čim več ljudi osebnostno razvilo do te stopnje, da bi lahko svoje individualne lastnosti tudi izražali. Pri skupinskih oblikah izobraževanja se individualne posebnosti ne morejo pokazati in uveljaviti, zato nimajo možnosti, da bi se razvijale. V preteklosti, v času množične proizvodnje in množičnega izobraževanja, je skupinsko organizirano izobraževanje (tečaji, seminarji, konference, simpoziji, posveti, večerne šole) ustrezalo, ker je moralo večje število posameznikov priti do istih izobraževalnih dosežkov, si pridobiti podobno znanje in konformizem je tako cvetel. Zdaj je zaposlovanje posamično in preverjajo se lastnosti ter posebna znanja posameznika. Zato je pomembna njegova drugačnost. Podlaga za to je individualno izobraževanje $v$ okviru osebnega izobraževalnega načrta. Individualizacija pri delu je odvisna od individualizacije izobraževanja in vzgoje.

\section{IZOBRAŽEVANJE ODRASLIH PONUIJA INDIVIDUALIZACIJO}

Organizacija šole temelji na skupinskem izobraževanju. Šele izobraževanje odraslih daje možnosti za individualizacijo. Na osnovi analize podatkov iz andragoške prakse je razvi- dno, da povpraševanje po individualnem izobraževanju, čeprav organiziranem neposredno $v$ institucijah, čedalje bolj narašča. Vse več ljudi povprašuje na primer po učenju tujih jezikov z individualnim mentorjem, konzultacijah in svetovanju med učenjem in po drugih osebnih izobraževalnih storitvah. To, da si mora izdelati vsak svoj izobraževalni načrt, če hoče postati enkraten in neponovljiv, marsikoga preseneti. Sam ga ne zna izdelati, niti ga ne zna izdelati za svoje otroke. Zato poišče strokovno pomoč.

Skupinske oblike izobraževanja niso nepomembne in pridejo še vedno $\mathrm{v}$ poštev pri doseganju vzgojno-izobraževalnih ciljev, vendar v okviru osebnega izobraževalnega načrta. Posameznik se jih udeležuje $\mathrm{z}$ določenim namenom, na tečajih in seminarjih se nauči to, kar se sam ne more naučiti. Spontano osebno izobraževanje jih dopolnjuje in povezuje $\mathrm{z}$ globalnimi vzgojnimi cilji. Tečaj, ki bi ga posameznik obiskoval, ne pomeni veliko, če ga ne dopolni še $\mathrm{z}$ drugimi oblikami individualnega izobraževanja. Učinek se izgublja, če ni povezan v celoto. Spontano izobraževanje ne sme potekati $\mathrm{v}$ samoti in brez strokovne pomoči, če hočemo, da bo učinkovito.

\section{SVETOVALNA MREŽA}

Organizacija mreže izobraževalno svetovalnih služb naj bi potekala na dveh ravneh. Osrednja izobraževalno svetovalna služba naj bi bila na sedežu andragoške ustanove. S »svojimi tipalkami« bi lahko segla do vsake vasi, do tam, kjer bi določila svetovalca ali sociokulturnega animatorja, pripravljenega sodelovati z ljudmi pri njihovem spontanem izobraževanju po neformalni poti. Za stike $\mathrm{z}$ ljudmi lahko animator občasno uporabi katerikoli javni prostor na vasi: gostilno, trgovino, šolo, obrtnikovo pisarno in podobno. Širjenje izobraževalnega svetovanja ne zahteva velikih finančnih vlaganj. Pomembno je, da odkrijemo v kraju pravega človeka, sposobnega 


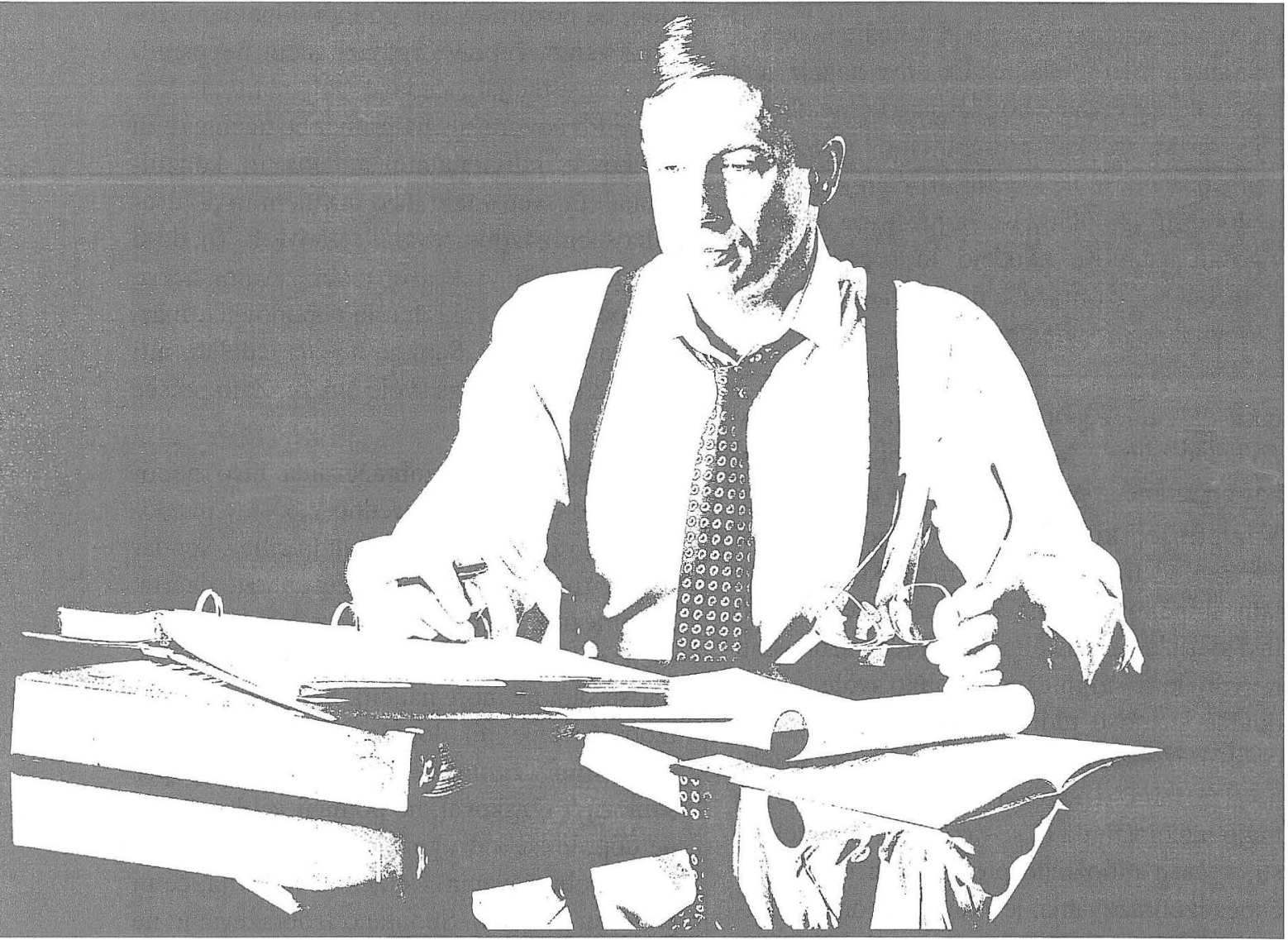

izobraževalnega svetovanja in sociokulturne animacije.

Učinkovitost vzgoje in izobraževanja je zelo odvisna od medsebojnega zaupanja, poznanstva, domačnosti in občutka pripadnosti med mentorjem in osebo, ki se uči. Takšno spora-

\section{Spontano izobra- zevanje poteka z osebnimi stiki.}

zumevanje omogoča tudi lažje reševanje neprijetnih situacij, na primer priznavanje neznanja, ker učeči čuti, da ni nevarnosti, da bi se $\mathrm{v}$ takem iskrenejšem odnosu $\mathrm{z}$ mentorjem lahko osmešil ali kako drugače onemogočil. Zato je pri razgovoru in iskanju pomoči zelo sprejemljiv. Sociokulturnega animatorja na vasi bi morali izbirati med domačini. V poštev bi prišli študenti, učiteljice, domačini, ki se znajo sami dobro učiti, knjižničarke ali drugi strokovnjaki za družboslovje in humanistiko, ki živijo v vasi. Izberemo ga po dveh merilih: ali ima smisel in veselje za delo z ljudmi in kako učinkovito se zna sam izobraževati? Lastno navdušenje bi namreč lahko hitro prenesel na druge.

Pri množičnih potrebah po izobraževanju ne iščemo rešitev $v$ poklicnih izobraževalcih, ampak v ljudeh, ki živijo skupaj. Pri tem upoštevamo predvsem krajevne vire za izobraževanje, ker poteka spontano izobraževanje z neposrednimi osebnimi stiki med ljudmi in pod vplivom okolja ter življenjskih razmer. To je tudi poroštvo, da se bo pridobljeno znanje lahko takoj uporabilo, ker je blizu stvarnosti. Znanje pride do veljave $\mathrm{v}$ odnosu do drugih ljudi, če se ujame $\mathrm{z}$ razmerami.

Spodbujanje in povezovanje spontanega 
osebnega izobraževanja posameznikov je odvisno tudi od tega, ali poznamo vzorce in strategije učenja, ki prevladujejo pri nas. A. Thomas je odkrival vzorce spontanega izobraževanja $\mathrm{v}$ Kanadi in $\mathrm{v}$ nekaterih južnoameriških državah in pri tem ugotovil, da se ti vzorci med seboj zelo razlikujejo. Če želi andragoška ustanova uvesti svetovalno-izobraževalno službo, mora začeti najprej raziskovati vzorce spontanega izobraževanja v svojem okolju.

\section{LITERATURA}

Jarvis, Peter (1992): Paradoxes of Learning, On Becoming an Individual in Society, Jossey Bass Publisher, San Francisco.

Hohlmeier, Monika (1999): Trendsetter der Weiterbildung, v: Das Forum, Zeitschrift der Volkshochschulen in Bayern, München, št. 2/1999, str. 2-5.

Frisching, Anette (1999): Schlüssel zum Erfolg: Die Mitarbeiternen, v: Das Forum, Zeitschrift der Volkcschulen in Bayer, München, št. 2/1999, str. 24-27.

Oinonen, Paavo (1995): The Challange of the Information Society, v: Life and Education in Findland, Helsinki, št. 4/1995, str. 36-43.

Field, John, Schuller, Tom (1999): Investigating the Learning Society, v: Studies in the Education of Adults, Vol. 31, št. 1/1999, str. 1-10.

Mayo, Peter (1997): Gramschi, Freire and Adult Education, Possibility for transformative action, Zed Books, London.

Usher, Robin, Edwards, Richard (1996): Postmodernism and Education, Routledge, London.

Goričar, Natalija (2000): Neformalno izobraževanje v Kostanjevici na Krki, Andragoška spoznanja, Ljubljana, let. 6 , št. 1, str. 63-74.

Findeisen, Dušana (2000): Lindemanovi filozofski temelji andragogike, Andragoška spoznanja, Ljubljana, let. 6, št. 1, str. 74-83.

Brečko, Daniela (1999): Vseživljenjski razvoj osebnosti, Andragoška spoznanja, let. 5, št. 3, str. 19-27.

Žnidaršič, Bojan (1999): Podeželje potrebuje aktivne državljane, Andragoška spoznanja, Ljubljana, let. 5, št. 4, str. 72-77.

Božič, Marta (1999): Aktivno življenje in skrb za lasten razvoj, Andragoška spoznanja, Ljubljana, let. 5, št. 4, str. 77-80.

Titmus, Colin (1995): Značilnosti izobraževalne ponudbe, Andragoška spoznanja, Ljubljana, let. 1, št. 1-2, str. 55-59.
Ličen, Nives (1996): Društva nekoč in danes z vidika skupnostnega izobraževanja, Andragoška spoznanja, Ljubljana, let. 2, št. 3, str. 45-53.

Findeisen, Dušana (1996): O skupnostnem izobraževanju in razvoju kraja, Andragoška spoznanja, Ljubljana, let. 2, št. 3, str. 27-33.

Krajnc, Ana (1996): Izobraževanje odraslih in lokalni razvoj, Andragoška spoznanja, Ljubljana, let. 2, št. 3, str. 23-27.

Nacke, Bernhardt, Dohmen, Günther (1996): Lebenslanges Lernen, $\mathrm{BMB}+\mathrm{F}$, Bonn. 